\title{
Arturo Valencia Islas, El descarrilamiento de un sueño: historia de los Ferrocarriles Nacionales de México, 1919-1949, México, Centro Nacional para la Preservación del Patrimonio Ferrocarrilero/El Colegio de México, 2017, 348 pp.
}

\author{
Jorge Fernando Beltrán Juárez ${ }^{1,}$ * [D 0000-0001-5257-4493 \\ ${ }^{1}$ Centro de Investigaciones y Estudios Superiores en Antropología Social, México. \\ * Correspondencia: jorge.beltran-@hotmail.com
}

El recurso literario que utiliza Arturo Valencia para titular su trabajo, además de sugerente para el lector, deja entrever inicialmente que el propósito del libro es explicar el fracaso (descarrilamiento) de un proyecto de desarrollo económico como lo fue la construcción y operación de ferrocarriles en México. Dicho proyecto gestado en el liberalismo porfirano y cuyo paso por la revolución, la áspera década de 1920 con la llegada de los sonorenses y la reivindicación obrera, el ascenso del cardenismo y el viraje político-económico de la década de 1940 con el avilacamachismo y el alemanismo generó una amplia lista de complicaciones que crearon problemas de fondo y a su vez impidieron que la empresa de transporte más importante del país: Ferrocarriles Nacionales de México, operara con eficiencia. Recorrer estas vías llevó al autor a descubrir círculos viciosos que fueron en contra de la rentabilidad, y cuya suma dio como resultado la quiebra de la empresa.

Indagar esta explicación colocó a Valencia en un escenario temático nada sencillo donde la historiografía ferroviaria en el país ha sido numerosa y variada -aunque no como se desearía. Esta ya larga tradición académica sitúa su origen con John Coatsworth en los cuarenta y su trabajo sobre el impacto económico de los ferrocarriles en México, lo que dio paso a investigaciones enfocadas en revisar los cambios que este medio de transporte generó en distintos niveles de escala. Sin embargo, una corriente relativamente nueva y que puede ser nombrada como revisionista, encabezada por investigadores como Paolo Riguzzi, Arturo Grunstein, Sandra Kuntz, Guillermo Guajardo, entre 
otros, planteó una serie de interrogantes que sólo puede ser contestada en perspectiva histórica: ¿por qué México no cuenta con un sistema ferroviario? y ¿qué propició que el sistema existente venido del porfiriato se volviera obsoleto?

Responder las dos interrogantes referidas lleva a inscribir el trabajo de Valencia en esa corriente revisionista sobre el buen funcionamiento empresarial, que cuestiona la eficiencia y los servicios de operación, así como la parte administrativa de los Ferrocarriles Nacionales de México. Un trabajo de esta envergadura había estado pendiente debido a que el cuestionamiento de la rentabilidad sólo se había realizado parcialmente y con casos específicos, o bien, en trabajos de mayor aliento. Para ello se puede revisar el trabajo de Sandra Kuntz, Ferrocarriles y vida económica en México (1996) o el caso particular del ferrocarril central (1995). El análisis administrativo por Arturo Grunstein para Ferrocarriles Nacionales es también un ejemplo de este eje de investigación al estudiar las perspectivas gerenciales (2008). En todo caso una veta de investigación distinta y cuyo foco de estudio es el desfase tecnológico la encontramos en Guajardo (2010).

En este sentido el acierto de Valencia es generar una explicación a partir del estudio de tres áreas específicas, mismas que van a ser su guía metodológica: la administrativa, la laboral y la financiera. El análisis de estos tres planos le permite exponer en el escenario actual los costos de la modernización, pues es poco conocido, como lo señala el autor, el hecho de que la liquidación de la empresa no significó la extinción de los adeudos, por lo que sigue generando gastos innecesarios al gobierno, mostrando aún los ecos dañinos a más de cien años de su creación. Esta sentencia vuelve al tema ferroviario un problema historiográfico vivo. Además, reabre la añeja discusión sobre el papel del Estado en su participación con la inversión privada, particularmente ahora que en México se tiene el proyecto del nuevo aeropuerto, o en un caso solitario la construcción del tren del sureste.

Para lograr su cometido el autor divide las 348 páginas que conforman su libro en seis capítulos, mismos que siguen un orden cronológico. En el primero construye la trama sobre el proceso que dio origen a la empresa estudiada previo a la revolución, fenómeno conocido como la consolidación. Para el segundo capítulo se analiza la incautación de la empresa en la revolución, la pretendida reorganización financiera y el ascenso obrero. En el tercer capítulo se explora el regreso de la empresa a manos privadas o, dicho de otra manera, el fin de la incautación, así como las diferentes líneas de acción que se consideraron para restaurar la eficiencia operativa, así como el tropiezo que significó la crisis de 1929. En el cuarto, se explora el panorama de la empresa una vez pasada la crisis del veintinueve y los primeros tres años del cardenismo. En el quinto capítulo se toca uno de las políticas cardenistas que causó gran revuelo en su momento: la nacionalización de los ferrocarriles y la cesión de la empresa a los trabajadores para su administración. Por último, se analiza el desarrollo de la empresa en el contexto de viraje político con el gobierno de Miguel Ávila Camacho y Miguel Alemán, donde el trasfondo fue la segunda guerra mundial y en consecuencia la existencia de proyectos de rehabilitación del sistema, así como la reanudación de la deuda ferrocarrilera. Este largo recorrido lleva al autor a tejer una serie de explicaciones considerando factores internos y externos, que le permite concluir porque llegó a la bancarrota una de las empresas más importantes del país.

Antes de rescatar algunos puntos de la trama de fondo es preciso destacar algunos detalles de forma. De ésta podemos decir que es una edición bien cuidada, el trabajo de escritura es pulcro, bien estructurado y de fácil lectura, aunque demanda un grado de familiaridad con conceptos de economía e historia. El texto es complementado con gráficas y tablas que permiten una mayor comprensión de aspectos particulares, pero para nada sencillos, como lo es el volumen de la deuda, 
el incremento o disminución del material rodante, o bien la parte orgánica de la empresa. En cuanto a fondo, el autor evidencia un amplio conocimiento del tema en la parte teórico-bibliográfico, así como de acervos documentales. Particularmente una de las novedades es la exploración de dos repositorios documentales que le arrojaron riqueza en la información: el Centro de Documentación e Investigaciones Ferroviarias, y el Archivo Histórico del Banco de México, además de explorar seis archivos más. Esta virtud le facilitó generar una discusión en el cuerpo del trabajo, que a su vez le permitió poner en escrutinio aseveraciones e hipótesis sobre el sistema de transporte, y a la par generar nuevas propuestas explicativas. En primer lugar, propone replantear la explicación que responsabiliza a los trabajadores de la quiebra de la compañía, sugiriendo que existe una serie de actores, en puestos medios y altos, no visible involucrada en la organización de la empresa, que de manera voluntaria o involuntaria provocó relaciones conflictivas entre: la empresa, el gobierno y el sindicato, entendiéndose como una contraposición de intereses. En segundo lugar, invita a repensar el papel de la deuda, ya que esta condicionó los ingresos brutos y en consecuencia la estabilidad de la empresa, importancia que no le ha sido otorgada en la historiografía.

Con lo anterior, y comenzando con algunos puntos nodales del trabajo, Valencia enfatiza que Ferrocarriles Nacionales padeció una crisis crónica debido a diversos factores, no obstante, la comprensión del problema sólo se logra cuando se dimensiona la profundidad de esas dificultades y no se piensa sólo en su conjunción. En este sentido, la primera contrariedad que condicionó el funcionamiento de los ferrocarriles fue la deuda derivada de la consolidación de 1908, y que daría origen a Ferrocarriles Nacionales. Este compromiso financiero estipulado en el contrato se dividió en deuda asumida y deuda propia, creando una deuda doble. La primera fue resultado de los compromisos financieros de las empresas constitutivas, que además dejan entrever un problema de sobre-capitalización, mientras que la segunda derivó del nuevo proceso de capitalización. Particularmente este segundo compromiso dejó observar la relación entre la empresa y el gobierno, pues este último fungió como accionista, fiador de la deuda y acreedor. Para el autor esta relación es importante porque sugiere que la suspensión del pago de intereses durante la revolución condicionó la renegociación del crédito para el país en la década de 1920, y fundamentalmente porque limitó los ingresos brutos de la empresa e impidió dirigir estos a mejoras materiales que hubiesen incrementado los ingresos. De ahí que rescate los procesos de restructuración de la deuda con el convenio De la Huerta-Lamont, la enmienda Pani y el convenio Montes de Oca-Lamont. Aunque el estudio de este tema lleva a develar que la deuda a más de cien años sigue siendo un problema para el gobierno mexicano, con lo cual se deja ver la función social de la historia, que es explicar problemas actuales.

Siguiendo el tema de la deuda y particularmente la emisión de bonos como uno de los medios para la capitalización, el autor detalla, la negativa que prohibió la exposición total de los bonos estipulados en el contrato. Esta acción impidió que la empresa realizara la construcción de nuevos trazos, compra de material, así como efectuar mejoras y adiciones. Este último punto incluía las mejoras y adiciones surgidas a partir de la consolidación, además de las derivadas de las empresas que formaron la compañía, como lo fue el del Ferrocarril Central, cuyas condiciones materiales eran inadecuadas al momento de la consolidación, lo que lleva a pensar en un rezago de mayor aliento. Dicho problema de modernización fue una constante a lo largo de la historia de la compañía, y así lo determinaron las diversas comisiones que estudiaron la funcionalidad de la empresa, tal es el caso de Colpitts, Thornton o la Railway Mission on México para la década de 1940. 
Este hondo análisis sobre la deuda que realiza Valencia sugiere a su vez considerar el tipo de moneda en que se adquirió, pues al parecer las crisis y la devaluación de la divisa mexicana dispararon en momentos particulares el monto de la deuda. Además, no se debe dejar de lado que el pago de esta, así como sus intereses debía realizarse en dólares, mientras que los ingresos por flete y pasaje se realizaban en pesos, lo que volvía más complicada la acción pagadera.

Ligado al problema de la deuda y al origen de la empresa, Valencia se detiene en la etapa de la revolución para observar las consecuencias reales en la compañía. Mucho se ha discutido sobre los efectos que este fenómeno armado generó, particularmente cuando se habla de ferrocarriles aún existe un consenso que argumenta que el efecto negativo más importante fue la destrucción del material rodante, las vías y puentes. No obstante, algunos investigadores cuestionan la tesis, tal es el caso de Valencia, quien sugiere que, si bien el daño material propiciado por las facciones revolucionarias fue de consideración, los perjuicios más importantes fueron los intangibles, como lo fue la ruptura de la disciplina laboral. Aunque en este caso la revolución significó el estallido de una olla de presión, puesto que las demandas de la clase trabajadora ya se habían canalizado a través de la organización obrera, manifestadas a través de huelgas durante el porfiriato. En consecuencia, la revolución aportó el marco preciso para reivindicar la justicia social, misma que se vio afianzada en la promulgación del artículo 123.

Empero, la conquista de derechos no fue sólo resultado de la exigencia obrera y así lo deja ver el autor. A lo largo del movimiento armado los obreros ferroviarios estuvieron en un vaivén entre las facciones revolucionarias, la afiliación dependía de quien hiciera las mejores propuestas reivindicativas. Para la década de 1920 y en el bullicio del ascenso de la nueva clase política el grupo obrero engrosó las filas de las bases electorales. Esta cooptación no fue malgastada por los trabajadores, conscientes de su papel estratégico en la economía nacional no desaprovecharon la oportunidad para obtener beneficios, por lo que pasaron de ser "un sujeto defensivo a un actor ofensivo." Esta práctica logró consolidarse con la evolución y formalización de las organizaciones obreras, las cuales a su vez fueron reconocidas por el Estado. La culminación de la organización obrera se dio en 1933 con la formación del Sindicato de Trabajadores Ferrocarrileros de la República Mexicana. Este organismo logró un posicionamiento clave, el cual se consolidó con el ascenso de Lázaro Cárdenas a la presidencia. Como muestra de esta relación se creó la Administración Obrera de los Trabajadores Ferrocarrileros de la República Mexicana, siendo esta cesión de la empresa su más grande conquista, puesto que el viraje político dado por Miguel Ávila Camacho y seguido por Miguel Alemán aplicó un retroceso en las políticas obreras impulsadas en el sexenio anterior, con ello se inauguró una nueva relación entre el Estado y los trabajadores ferrocarrileros.

Sin embargo, el ascenso obrero, dice el autor, se volvió un problema en varios sentidos. En primer lugar, al término de la revolución y con la afiliación a centrales obreras y grupos políticos lograron incrementar 50 \% el número del personal, lo que significó el aumento en la partida destinada a salarios. El problema es que el incremento del número de empleados no fue correspondido con un aumento en el kilometraje de vías, además de que el tonelaje por flete tampoco había incrementado considerablemente, lo que lleva a la conclusión de que hubo un exceso de personal, que además constantemente demandaba mejoras salariales, demandas que no podían ser cumplidas por los bajos rendimientos de la empresa. Estas exigencias constantes terminaron por minar momentos que pudieron apuntalar el buen funcionamiento, como lo fue la "buena" recuperación de las finanzas de la empresa después de la crisis de 1929. Este horizonte alentador se vio disipado 
con la consolidación del sindicato y las presiones obreras para incrementar los salarios y recontratar personal cesado durante la crisis. El momento quizá más complicado para la empresa fue durante el cardenismo con la ruptura casi total de la disciplina obrera.

No obstante, sugiere Valencia, que esta idea de homogeneidad o cohesión obrera debe ser tomada con cuidado, puesto que a pesar de que los trabajadores lograron la formación del sindicato ferrocarrilero siguió presente la división, incluso hasta finales de la década de 1940, lo que da pauta para explicar conflictos intergremiales como los que se dieron durante la administración obrera donde el eje del problema radicó en cómo manejar la empresa y la indisciplina. Esta división sugiere el autor, encuentra explicación en el arraigo identitario de grupos obreros nucleares, donde el número menor de miembros fortalecía las relaciones entre las partes. Esta propuesta no sólo da luz a los claroscuros de la clase obrera de Ferrocarriles Nacionales, también puede dar pauta para entender los lentos procesos de conformación obrera en otras compañías ferroviarias del país como el caso de Ferrocarril Sud Pacífico de México o Ferrocarriles Unidos de Yucatán. Pues hasta hoy, la explicación dada atribuye el lento transitar del mutualismo al sindicalismo a una falta de lazos comunicantes con las principales centrales obreras del país.

En cuanto a la parte administrativa el tema no es menos complejo, ya que para identificar el tipo de administración que tuvo la empresa debemos primero señalar un periodo. Esta tarea es bien resuelta por Valencia al referir la administración privada, estatal, mixta, la incautación, una administración obrera, y de nuevo la reincorporación de la empresa al Estado. Lo que en consecuencia también lleva a pensar en los tipos de propiedad por los que transitó la compañía: privada, mixta, y estatal. Cada una de estas administraciones tuvo que afrontar los problemas financieros, tecnológicos y de servicio, dentro de los cuales se encontraron la deuda contraída, el rezago tecnológico, la desorganización administrativa, los conflictos con los grupos obreros y posteriormente con el sindicato.

En este tenor, la consolidación redirigió la política liberal del porfiriato para dar paso al control estatal. En esta parte Valencia profundiza en el debate que se ha suscitado sobre la motivación de Limantour para intervenir en un negocio privado, por lo que replantea que más que un temor, como se ha sugerido, de la formación de un monopolio extranjero en una industria estratégica, el principal objetivo era buscar participación en el mercado ferroviario. Sin embargo, la participación mayoritaria del Estado en una empresa que había surgido con carácter privado contrapuso dos visiones de operatividad. Por un lado, el carácter privado apostaba por un sistema administrativo rígido y de disciplina. Mientras que el perfil estatal, si bien compartía el discurso, desdibujó la funcionalidad y relajó la disciplina al solapar comportamientos perjudiciales.

Muestra de estas contradicciones son expuestas por Valencia cuando analiza el papel que desempeñó Mariano Cabrera en la dirección de la empresa, pues además de no dimensionar la mala situación financiera de la compañía permitió el incremento del número de trabajadores, lo que significó una carga adicional a las finanzas de la empresa al exigir mayores erogaciones para el pago de salarios. En el caso contrario, la administración de Javier Sánchez Mejorada desempeñada en la crisis de 1929 apostó por la reducción de personal, entre otras medidas para mejorar las finanzas. Sin embargo, las protestas de los grupos obreros que además encontraron respaldo en el Estado terminaron por obstaculizar las medidas correctoras. Un ejemplo más de las contradicciones administrativas fue la creación de la Administración Obrera, pues además de incrementar la indisciplina se cometió el equívoco de dejar a los obreros un doble papel: ser patronos y empleados al mismo tiempo. 
Los retos que enfrentaron las administraciones no fueron sencillos como lo señala el autor, ya que en un plazo de mediana duración tuvieron que resolver las cargas financieras generadas por las jubilaciones y sortear otros retos. En este renglón Valencia coloca el problema de la competencia automotriz como factor de desplazamiento para el ferrocarril, el cual no sólo fue posible por su flexibilidad, sino porque la operación ferroviaria se lo permitió al no resolver sus problemas tecnológicos, administrativos, de expansión, de equipamiento, entre otros. Este tema está pendiente de un estudio acucioso que lleve a comprender este proceso de lenta transición, pues, a diferencia del ferrocarril, el autotransporte no implicó el acarreo de mayores volúmenes de carga como el ferrocarril lo hacía.

Finalizando, es preciso decir, que el trabajo de Valencia por las dimensiones que alcanza muy probablemente se volverá una obra de consulta obligada para todos aquellos interesados en el tema ferroviario, ya que además de cubrir un vacío historiográfico importante las reflexiones que genera dan paso a pensar en posibles nuevos temas de investigación o bien revisar algunos ya planteados. Entre estos últimos el mismo Valencia señala el tema de la deuda, el cual en su opinión requiere una revisión que conteste otras interrogantes. En el caso de los temas novedosos se podría pensar en realizar trabajos desde la visión empresarial para otros casos concretos de la realidad nacional, o bien, hacer estudios comparativos con empresas de grandes dimensiones asentadas en otros espacios nacionales. 